\title{
Short-lived Radon Daughter Deposition Activity on Ground Surface Carried by Rainfall
}

\author{
Hironobu HaYAKaWA*,*1
}

\author{
(Received March 13, 1986)
}

(Accepted November 4, 1986)

\begin{abstract}
This paper describes a convenient and easy method of evaluating the short-lived radon daughters, ${ }^{214} \mathrm{~Pb}(\mathrm{RaB})$ and ${ }^{214} \mathrm{Bi}(\mathrm{RaC})$, deposition activity on ground surface carried by rainfall in situ. Data of variations in the deposition activity on ground surface calculated from the continuous gamma radiation made at several sites for a period of nine years are given together with data of precipitation.

It is concluded from the observations that the annual $\mathrm{Ra}(\mathrm{B}+\mathrm{C})$ deposition activity lies within the range $4,600-12,000 \mathrm{pCi} \mathrm{cm}^{-2} \mathrm{y}^{-1}$, which depends on the annual precipitation. From the annual mean radon $\left({ }^{222} \mathrm{Rn}\right)$ exhalation rate (UNSCEAR 1982), the annual precipitation on the terrestrial parts of the earth (reference data), and the annual mean specific activity of $\mathrm{Ra}(\mathrm{B}+\mathrm{C})$ in rainwater (observation), we calculate the ratio of $\mathrm{Ra}(\mathrm{B}+\mathrm{C})$ atom deposited on the ground to ${ }^{222} \mathrm{Rn}$ released from the ground. This ratio is less than $1 \%$. This means that almost all of the short-lived radon daughters in the atmosphere are not caught by rain and decayed to the long-lived radon daughters in the atmosphere.
\end{abstract}

KEY WORDS: short-lived radon daughters, deposition activity, precipitation, monitoring, gamma radiation, exposure rate

\section{INTRODUCTION}

Fukui Environmental Radiation Monitoring Laboratory has been continuously monitoring the external radiation at 10 locations (from 1 to over $10 \mathrm{~km}$ distance from nuclear power plant sites) in Fukui Prefecture, Japan, since January 1977, including meteorological as well as temporal variations. In 1980, the eleventh monitoring station was constructed. ${ }^{1)}$

Since September 1979, there has been no increase in exposure rate due to plume exposure rate. Therefore, the variations of the external gamma radiation observed in our monitoring system are useful in studying the variations of natural radioactivity. Under these conditions, the numerous fluctuation of the exposure rate, which can be seen during rainfall, are shown in Fig. 1.

* 早川博信

*1 Environmental Radiation Monitoring Laboratory of Fukui Pref ; Yoshiko-37, Tsuruga-shi, 914 Japan. 福井県環境放射線監視センター; 敦賀市吉河 37 号 1 番地 (宁914)
It is said that the increases in exposure rate of several microroentgens per hour at ground level during precipitation are caused by the natural radioactivity in rainwater which consists mainly of ${ }^{214} \mathrm{~Pb}(\mathrm{RaB})$ and ${ }^{214} \mathrm{Bi}(\mathrm{RaC}) .{ }^{2)}$ We have already studied the dependency of $\operatorname{Ra}(B+C)$ specific activity on both concentration of radon in cloud and rate of rainfall. ${ }^{3)}$ We would like to deal with the radioisotopes of $\mathrm{RaB}$ and $\mathrm{RaC}$ in rainwater from a different point of view. Namely, the purpose of this paper is to estimate what percentage of $\mathrm{RaB}$ and $\mathrm{RaC}$ in the atmosphere (both of which are borne by ${ }^{222} \mathrm{Rn}$ released from the ground), is deposited on the ground surface by rain. In other words, the purpose is to estimate what percentage of $\mathrm{RaB}$ and $\mathrm{RaC}$ in the atmosphere (shown in the scheme of ${ }^{222} \mathrm{Rn}$ and its decay chain; ${ }^{222} \mathrm{Rn} \rightarrow$ $\mathrm{RaA}\left({ }^{218} \mathrm{Po}\right) \rightarrow \mathrm{RaB} \rightarrow \mathrm{RaC} \rightarrow \mathrm{RaC}^{\prime}\left({ }^{214} \mathrm{Po}\right) \rightarrow \mathrm{RaD}$ $\left.\left({ }^{210} \mathrm{~Pb}\right) \rightarrow\right)$, is caught by rain and carried to the ground. When we know this percentage, it is possible for us to divide the excessive ${ }^{210} \mathrm{~Pb}$ in the soil between the ${ }^{210} \mathrm{~Pb}$ which is borne by $\mathrm{RaC}$ on the ground after deposition and the ${ }^{210} \mathrm{~Pb}$ which is 


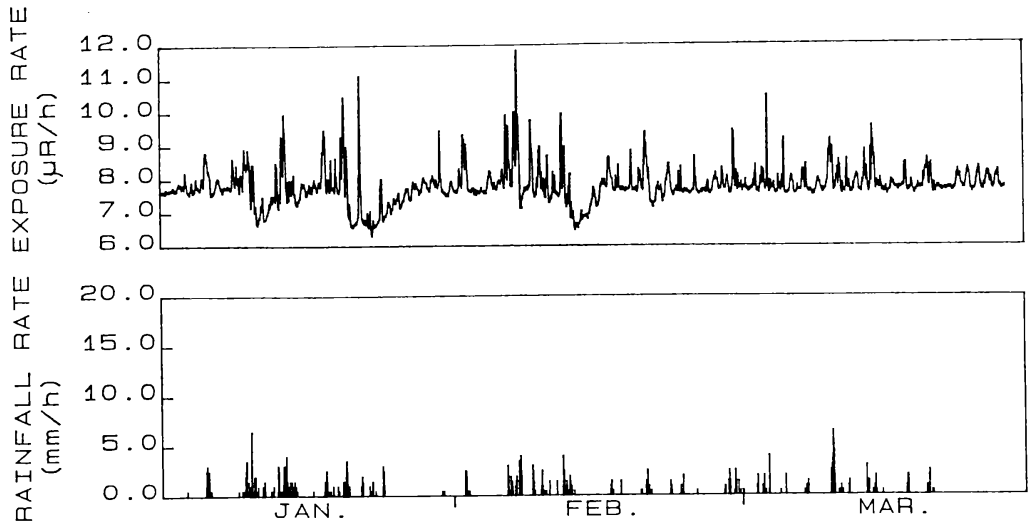

Fig. 1 One-hour values of the exposure rate and the rainfall rate (at No. 1 monitoring station, Jan.-Mar. 1983).

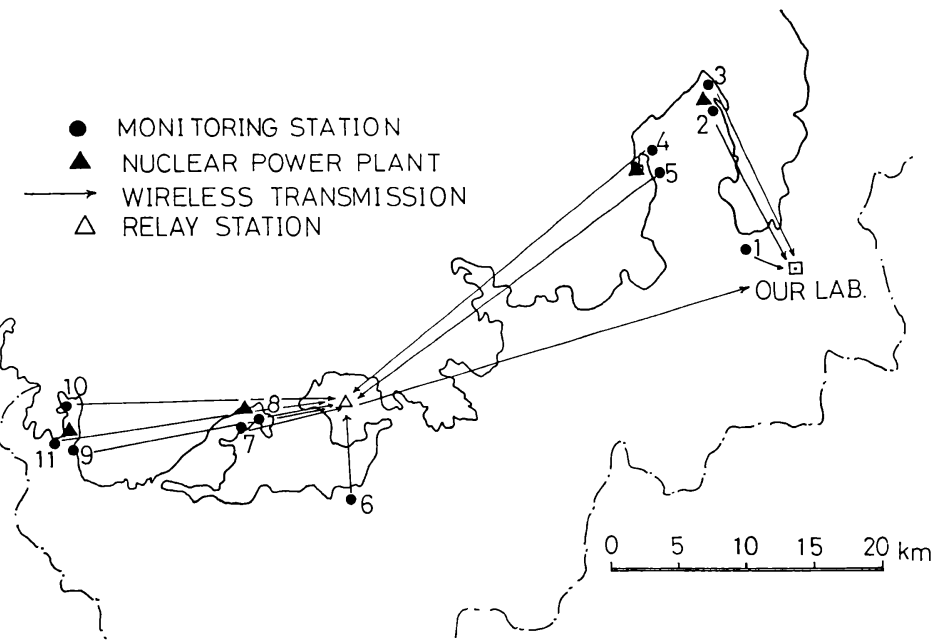

Fig. 2 On-line monitoring system.

already in the atmosphere before deposition. We will discuss the balance of ${ }^{222} \mathrm{Rn}$ released from the ground and its daughters deposited on the ground, not with the activity ratio, but with the atom ratio.

These points of view are new, and are not found in previous research on the natural radioactivity in rainwater. We believe that the worthiness of this paper is not in the accuracy of the value obtained from the final result, but in setting forth this new point of view. Accordingly, when we quote the exhalation rate of ${ }^{222} \mathrm{Rn}$ and the other values which are used in the calculation, the adoption of these values may not necessarily be precise. This should have no effect on the essential worth of this paper, which we believe merits further discussion.

\section{METHOD}

\section{Locations of monitoring stations}

Figure 2 shows the locations of the monitoring stations. Of eleven stations, rainfall rate is measured at numbers 1, 2, 4, 6, 8, 9 and 11. Accordingly, data obtained from these stations have been used to study the $\mathrm{Ra}(\mathrm{B}+\mathrm{C})$ deposition activity on the ground carried by rainfall.

Table 1 gives the annual mean exposure rate without rain measured at these stations during 1977-1985. 
Table 1 Annual mean exposure rate without rain 1977-1985 (uR/h)

\begin{tabular}{lcccccc}
\hline Station No. & 1 & 2 & 4 & 6 & 8 & 9 \\
\hline Exposure rate & 7.51 & 8.07 & 7.50 & 5.09 & 4.26 & 4.56 \\
Sigma & 1.25 & 1.34 & 1.17 & 0.79 & 0.67 & 0.70 \\
\hline
\end{tabular}

\section{Calculation of radioactivity of rainwater from exposure rate}

The monitoring system to measure the exposure rate, which consists of a 2 -in. by 2 -in. $\mathrm{NaI}(\mathrm{Tl})$ counter, has been described in detail elsewhere. ${ }^{3)}$ We will now describe a method calculating the $\mathrm{Ra}(\mathrm{B}+\mathrm{C})$ activity of rainwater from the additional exposure rate at ground level during rain.

The exposure rate can be related to the radioactivity of rainwater in a somewhat complex manner. This relation may be described by the following integral equation:

$$
X(t)=\int_{o}^{t} A\left(t^{\prime}\right) K\left(t, t^{\prime}\right) \mathrm{d} t^{\prime}
$$

in which $X(t)$ is the exposure rate at time $t$, $A\left(t^{\prime}\right)$ is the radioactivity of rainwater transported to the ground surface per unit time at time $t^{\prime}$, and $K\left(t, t^{\prime}\right)$ is the exposure rate at time $t$ which is produced by unit activity transported by rainwater at time $t^{\prime}$.

From the work of Minato, ${ }^{4)}$ Eq. (1) is solved in the following form:

$$
\begin{aligned}
X_{i+1}= & \left(\frac { b } { \lambda _ { \mathrm { B } } } \left(1-\mathrm{e}^{\left.-\lambda_{\mathrm{B}} \Delta t_{I}\right)}+\frac{c}{\lambda_{\mathrm{C}}}\left(1-\mathrm{e}^{\left.-\lambda_{\mathrm{C}} \Delta t_{I}\right)}\right) A_{I}\right.\right. \\
& +\mathrm{e}^{-\lambda_{\mathrm{B}} \Delta t_{I}} \Gamma_{i}{ }^{\mathrm{B}}+\mathrm{e}^{-\lambda \mathrm{c} \Delta t_{I}} \Gamma_{i} \mathrm{C}
\end{aligned}
$$

Here

$$
\begin{gathered}
\Delta t_{I}=t_{i+1}-t_{i} \\
b=\left(q \mathrm{~B}+\frac{\lambda_{\mathrm{C}}}{\lambda_{\mathrm{C}}-\lambda_{\mathrm{B}}} q \mathrm{C}\right) / 2 \\
c=\left(1-\frac{\lambda_{\mathrm{C}}}{\lambda_{\mathrm{C}}-\lambda_{\mathrm{B}}}\right) q \mathrm{C} / 2 \\
\Gamma_{i}{ }^{\mathrm{x}}=\mathrm{e}^{-\lambda_{\mathrm{X}} \Delta t_{I-1}} \Gamma_{i-1}^{\mathrm{X}}+\frac{x}{\lambda_{\mathrm{x}}}\left(1-\mathrm{e}^{-\lambda_{\mathrm{X}} \Delta t_{I-1}}\right) A_{I-1}
\end{gathered}
$$

$\mathrm{X}=\mathrm{B}$ or $\mathrm{C}, \quad x=b$ or $c, \quad \Gamma_{0} \mathrm{x}=0$

where $\lambda$ is the decay constant, $A_{I}$ is the radioactivity of rainfall within the time interval from $t_{i}$ to $t_{i+1}$, which exhibits no time variation. The capitals of $\mathrm{B}$ and $\mathrm{C}$ are the subscripts of refering to $\mathrm{RaB}$ and $\mathrm{RaC}$, respectively, $q \mathrm{~B}$ and $q \mathrm{C}$ are the exposure rates due to infinite plain sources having unit activity of $\mathrm{RaB}$ and $\mathrm{RaC}$, respectively. These values have been calculated as a function of height above the ground surface.

In Eq. (2) $X_{i+1}$ is the exposure rate at time $t_{i}$. Our data of exposure rate stored on magnetic tape, however, are the hourly average data $\left(\bar{X}_{i+1}\right)$. Accordingly, we can determine $X_{i+1}$ by integrating $X_{i+1}$ from $t_{i}$ to $t_{i+1}$ when $\Delta t_{I}$ in Eq. (2) is replaced by $\left(t-t_{i}\right)$. It can be written in the following equation.

$$
\bar{X}_{i+1}=\left(\int_{t_{i}}^{t_{i+1}} X_{i+1} \mathrm{~d} t\right) /\left(t_{i+1}-t_{i}\right)
$$

Substituting Eq. (2) into Eq. (5), we obtain:

$$
A_{I}=\frac{\bar{X}_{i+1}-\frac{\lambda}{\lambda_{\mathrm{B}} \Delta t}\left(1-\mathrm{e}^{-\lambda_{\mathrm{B}} \Delta t}\right) \Gamma_{i}^{\mathrm{B}}-\frac{1}{\lambda_{\mathrm{C}} \Delta t}\left(1-\mathrm{e}^{-\lambda_{\mathrm{C}} \Delta t}\right) \Gamma_{i}{ }^{\mathrm{C}}}{\frac{b}{\lambda_{\mathrm{B}}}+\frac{c}{i_{\mathrm{C}}}-\left(\frac{1}{\lambda_{\mathrm{B}} \Delta t}\right)\left(\frac{b}{\lambda_{\mathrm{B}}}\right)\left(1-\mathrm{e}^{-\lambda_{\mathrm{B}} \Delta t}\right)-\left(\frac{1}{\lambda_{\mathrm{C}} \Delta t}\right)\left(\frac{c}{\lambda_{\mathrm{C}}}\right)\left(1-\mathrm{e}^{-\lambda_{\mathrm{C}} \Delta t}\right)}
$$

Where $A_{I}$ is the hourly average radioactivity at ground level $\left(\mathrm{pCi} / \mathrm{cm}^{2}\right)$, and $\bar{X}_{i+1}$ is the hourly average exposure rate $(\mathrm{uR} / \mathrm{h})$, because the time interval, $\Delta t$, is chosen to be 1 hour. In order to examine the relationship between the $\mathrm{Ra}(\mathrm{B}+\mathrm{C})$ deposition activity and the amounts of rainfall, we have used data of the exposure rate obtained from a continuous on-line monitoring system using a $\mathrm{NaI}(\mathrm{Tl})$ scintillation counter together with data of precipitation.

\section{RESULTS AND DISCUSSION}

1. Dependency of $\operatorname{Ra}(B+C)$ annual deposition activity on annual precipitation

Figure 3 shows the monthly $\mathrm{Ra}(\mathrm{B}+\mathrm{C})$ deposition activity and the monthly precipitation from 1977 to 1985 at No. 1 monitoring station. The peak in January 1981, is attributable to the so-called " 81 Heavy Snow," when the height of piled snow was over $2 \mathrm{~m}$ in our dwelling area. The data illus- 


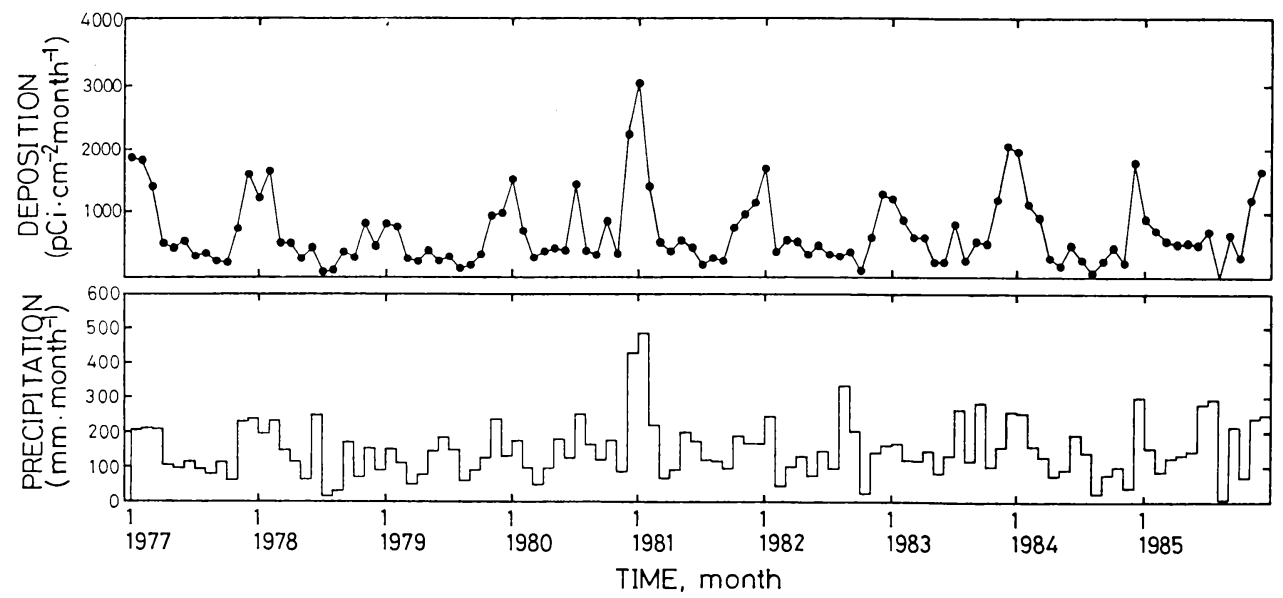

Fig. $3 \mathrm{Ra}(\mathrm{B}+\mathrm{C})$ deposition activity on ground surface carried by rainfall and precipitation (At No. 1 monitoring station, 1977-1985).

Table $2 \mathrm{Ra}(\mathrm{B}+\mathrm{C})$ annual deposition activity and annual precipitation (1977-1985). Upper: activity $\left(\times 10^{2} \mathrm{pCi} / \mathrm{cm}^{2} \mathrm{y}\right)$, lower: precipitation $(\mathrm{mm} / \mathrm{y})$

\begin{tabular}{lrrrrrrr}
\hline St. No. & 1 & \multicolumn{1}{c}{2} & \multicolumn{1}{c}{4} & \multicolumn{1}{c}{6} & \multicolumn{1}{c}{8} & \multicolumn{1}{c}{9} & 11 \\
\hline 1977 & 101.6 & 106.9 & 80.8 & 80.1 & 83.9 & 74.4 & \\
& 1756.0 & 1930.0 & 1461.5 & 1550.5 & 1507.5 & 1498.5 & \\
1978 & 68.3 & 75.2 & 53.1 & 58.4 & 64.4 & 65.8 & \\
& 1530.5 & 1538.5 & 1259.0 & 1362.5 & 1242.0 & 1406.0 & \\
1979 & 57.6 & 91.6 & 61.9 & 61.9 & 68.2 & 63.6 & \\
& 1519.0 & 1918.0 & 1590.0 & 1762.0 & 1612.5 & 1764.5 & \\
1980 & 89.8 & 123.1 & 74.6 & 75.9 & 83.1 & 82.8 & \\
& 1954.0 & 2377.5 & 1807.5 & 1814.5 & 1571.0 & 1797.5 & \\
1981 & 101.0 & 115.9 & 82.2 & 76.2 & 85.5 & 80.5 & 54.7 \\
& 2097.0 & 2074.5 & 1835.5 & 1721.5 & 1653.5 & 1751.5 & 1087.5 \\
1982 & 72.1 & 90.7 & 67.3 & 60.8 & 68.8 & 66.9 & 82.9 \\
& 1700.0 & 1838.0 & 1395.5 & 1584.0 & 1450.5 & 1585.0 & 1719.0 \\
1983 & 93.5 & 101.8 & 70.9 & 70.1 & 73.9 & 75.5 & 93.9 \\
& 1952.5 & 2147.5 & 1643.0 & 1724.0 & 1449.0 & 1717.0 & 1994.5 \\
1984 & 81.3 & 68.5 & 62.6 & 53.5 & 46.5 & 57.2 & 77.4 \\
& 1584.0 & 1731.0 & 1252.0 & 1191.0 & 947.5 & 1170.5 & 1477.5 \\
1985 & 83.6 & 92.8 & 74.1 & 57.6 & 68.4 & 64.3 & 84.9 \\
& 2007.0 & 2130.0 & 1905.0 & 1809.5 & 1686.5 & 1760.0 & 2103.0 \\
\hline
\end{tabular}

trated in Fig. 3 seem to indicate that the monthly $\mathrm{Ra}(\mathrm{B}+\mathrm{C})$ deposition activity is approximately an increasing function of the amount of precipitation. Table 2 gives the $\mathrm{Ra}(\mathrm{B}+\mathrm{C})$ annual deposition activity during 1977-85 together with annual precipitation. These deposition activities do not depend upon the annual mean exposure rate without rain at each station shown in Table 1. Since the exposure rate without rain at ground level reflects the concentration of radionuclides in soil, the non-dependency mentioned above seems to indicate that the $\mathrm{Ra}(\mathrm{B}+\mathrm{C})$ deposition activity on the ground at a certain site may not depend on the concentration of ${ }^{222} \mathrm{Rn}$ in soil at that site. Figure 4 shows the correlation between the annual $\mathrm{Ra}(\mathrm{B}+$ C) deposition activity and the annual precipitation. This figure clearly shows the dependency of the $\mathrm{Ra}(\mathrm{B}+\mathrm{C})$ deposition activity on precipitation.

2. Deposition efficiency of $\operatorname{Ra}(B+C)$ in the atmosphere by rain

$\mathrm{Ra}(\mathrm{B}+\mathrm{C})$ in rainwater observed on the ground are the $\mathrm{Ra}(\mathrm{B}+\mathrm{C})$ caught by rain in the atmosphere 


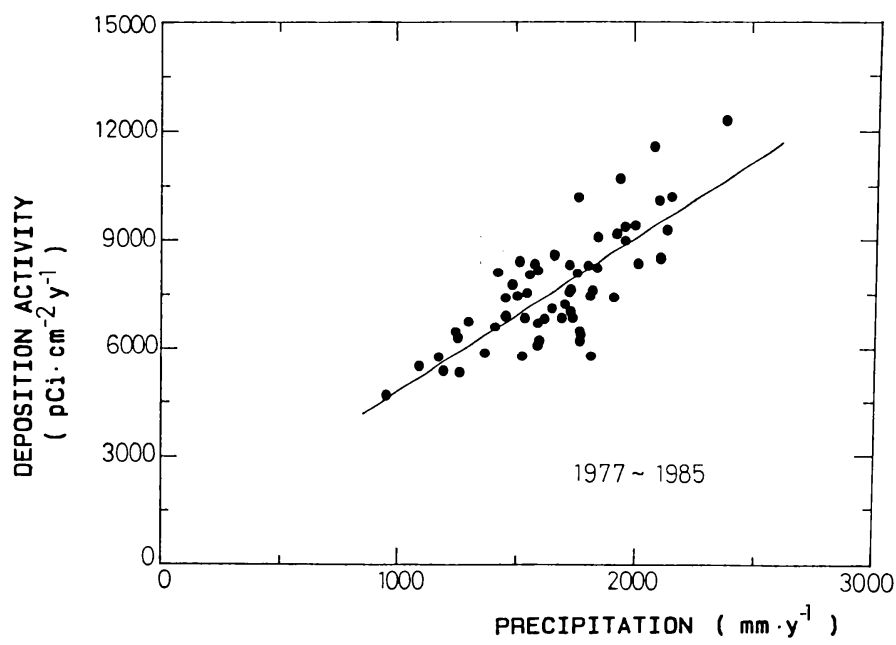

Fig. 4 Correlation between annual $\mathrm{Ra}(\mathrm{B}+\mathrm{C})$ deposition activity and annual precipitation.

Table 3 Annual mean specific activity $\mathrm{Ra}(\mathrm{B}+\mathrm{C})$ of rainwater.

\begin{tabular}{lrrrrrrrrr}
\hline & 1977 & 1978 & 1979 & 1980 & 1981 & 1982 & 1983 & 1984 & 1985 \\
\hline Mean specific activity & 51 & 45 & 39 & 45 & 48 & 44 & 46 & 46 & 39 \\
Samples & 5707 & 5342 & 5576 & 6696 & 6114 & 5092 & 5886 & 5099 & 5804 \\
\hline
\end{tabular}

and carried to the ground. $\mathrm{Ra}(\mathrm{B}+\mathrm{C})$ in the atmosphere are the daughters of ${ }^{222} \mathrm{Rn}$ in the atmosphere. ${ }^{222} \mathrm{Rn}$ in the atmosphere is released from the ground. (Here we neglect ${ }^{222} \mathrm{Rn}$ released from the ocean, because its quantity is much smaller than that from the ground.5)). We know that there are many complicated processes in which ${ }^{222} \mathrm{Rn}$ released from the ground is decayed to $\mathrm{RaA}$ first, and in the end $\mathrm{RaC}$ is caught by rain. ${ }^{6}$ ) But in this section, we treat the deposition efficiency of $\mathrm{Ra}(\mathrm{B}+\mathrm{C})$ in the atmosphere as the atom balance of $\mathrm{Ra}(\mathrm{B}+\mathrm{C})$, which is defined as the ratio of the exhalation ${ }^{222} \mathrm{Rn}$ atom and the $\mathrm{Ra}(\mathrm{B}+\mathrm{C})$ atom in rainwater observed on the ground. The reason why we do so has already been stated in the introduction. Namely, the purpose of this section is to estimate what percentage of $\mathrm{Ra}(\mathrm{B}+\mathrm{C})$ atom borne by ${ }^{222} \mathrm{Rn}$ in the atmosphere is caught by rain and carried to the ground.

$$
\text { Atom Balance }=\frac{\left(N_{\mathrm{RaB}}+N_{\mathrm{RaC}}\right)_{\text {ON THE GROUND }}}{\left(N_{\mathrm{Rn}}\right)_{\mathrm{FROM}} \text { THE GROUND }}
$$

where $N_{\mathrm{RaB}}, N_{\mathrm{RaC}}$ is the amounts of $\mathrm{RaB}$ and $\mathrm{RaC}$ deposited on the ground in one year, respectively. And $N_{\mathrm{Rn}}$ is the amounts of ${ }^{222} \mathrm{Rn}$ released from the ground in one year. We calculate the Eq. (7) above the terrestrial parts of the earth.

On the denominator of Eq. (7): We adopt the

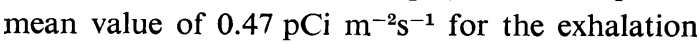
rate of ${ }^{222} \mathrm{Rn}$, which is quoted from UNSCEAR 1982.7) Since the terrestrial area on the earth is $1.5 \times 10^{14} \mathrm{~m}^{2}$, the total activity of ${ }^{222} \mathrm{Rn}$ released from the ground in one year is $2.2 \times 10^{21} \mathrm{pCi}$.

That is, $\left(\lambda_{\mathrm{Rn}} N_{\mathrm{Rn}}\right)_{\mathrm{FROM}}$ THE GROUND

$$
=2.2 \times 10^{21} \mathrm{pCi} / \text { year. }
$$

Accordingly, $\left(N_{\mathrm{Rn}}\right)_{\mathrm{FROM}}$ THE GROUND

$$
=3.8 \times 10^{25} \text { atom/year. }
$$

On the numerator of the Eq. (7): An amount of precipitation on the terrestrial parts in one year is $1.0 \times 10^{20} \mathrm{~g}^{8)} \quad$ Therefore, when we know the mean $\mathrm{Ra}(\mathrm{B}+\mathrm{C})$ activity in rainwater, the $\mathrm{Ra}(\mathrm{B}+\mathrm{C})$ deposition activity on the terrestrial parts in one year can be estimated. We have, however, few observed values of the $\mathrm{Ra}(\mathrm{B}+\mathrm{C})$ specific activity in rainwater. Table 3 gives the annual mean specific activity of $\mathrm{Ra}(\mathrm{B}+\mathrm{C})$ in rainwater in our area for nine years. The mean for nine years is $45 \mathrm{pCi} / \mathrm{ml}$. In Sweden, these values are measured ranging between 30 and $60 \mathrm{pCi} / \mathrm{ml}$ (300 samples). ${ }^{2}$ The geometric mean in the USA is $47 \mathrm{pCi} / \mathrm{ml}(348$ samples). ${ }^{9} \quad$ This value is calculated by multiplying 


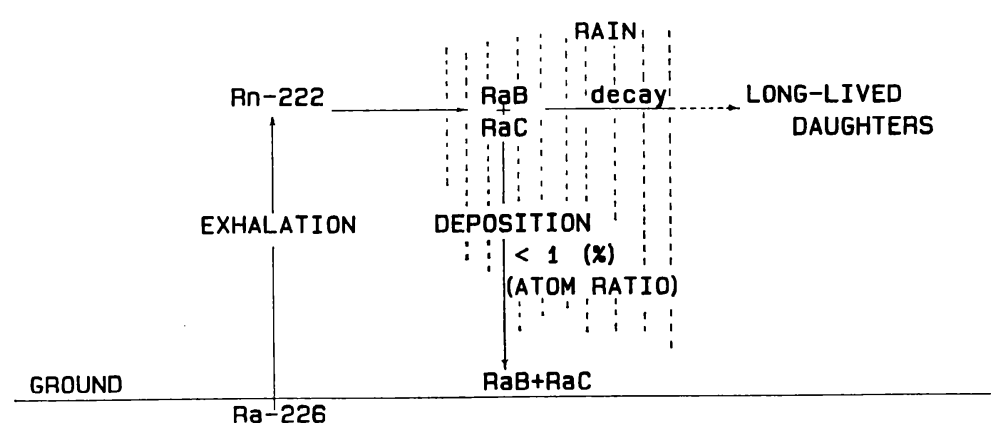

Fig. 5 Illustrated conclusion.

the geometric mean of an additional exposure rate per unit precipitation (which is given in the original paper ${ }^{9}$ ), by the conversion factor calculated by S. Minato. ${ }^{4)}$ These three values are very similar. We adopt representative value of $45 \mathrm{pCi} / \mathrm{ml}$ for the global mean specific activity of $\mathrm{Ra}(\mathrm{B}+\mathrm{C})$ in rainwater, even though the sample numbers are not necessarily enough. From the amount of precipitation on the terrestrial parts in one year and the annual mean specific activity of $\mathrm{Ra}(\mathrm{B}+\mathrm{C})$ in rainwater, the total deposition activity of $\operatorname{Ra}(B+C)$ on the terrestrial parts in one year is $4.5 \times 10^{21} \mathrm{pCi}$.

That is, $\left(\lambda_{\mathrm{RaB}} N_{\mathrm{RaB}}+\lambda_{\mathrm{RaC}} N_{\mathrm{RaC}}\right)_{\text {ON }}$ THE GROUND $=$ $4.5 \times 10^{21} \mathrm{pCi} /$ year. We assume that both the radioactivity of $\mathrm{RaB}$ and of $\mathrm{RaC}$ in rainwater are equal.

Accordingly, $\left(N_{\mathrm{RaB}}+N_{\mathrm{RaC}}\right)$ ON THE GROUND $=3.3$ $\times 10^{23}$ atom/year. Note the released activity of ${ }^{222} \mathrm{Rn}$ from the ground is less than the deposition activity of $\mathrm{Ra}(\mathrm{B}+\mathrm{C})$ on the ground. This is because the half life of ${ }^{222} \mathrm{Rn}$ is longer than its daughters. On the other hand, the atom balance defined in Eq. (7) is $0.87 \%$. This means that almost all of the short-lived radon daughters in the atmosphere are not caught by rain and decayed to the long-lived radon daughters in the atmosphere. Namely, the excessive ${ }^{210} \mathrm{~Pb}$ in the soil is almost always borne in the atmosphere before depostion. Figure 5 gives the illustrated conclusion.

In order to determine aerosol residence time in he atmosphere, activity ratio of ${ }^{222} \mathrm{Rn}$ and ${ }^{210} \mathrm{~Pb}$ has been used. One of the assumptions in such determination is that the short-lived immediate progeny of ${ }^{222} \mathrm{Rn}$ can be presumed to be predominantly converted to ${ }^{210} \mathrm{~Pb}$ before any major removal occurs. Our results support the validity of this assumption.

ACKNOWLEDGEMENT: The author is grateful to Prof. Dr. Y. IKeBE of Nagoya University for many valuable suggestions. Thanks are also due to Dr. S. Minato of the Government Industrial Research Institute, Nagoya, for many good suggestions.

\section{REFERENCES}

1) H. HaYama; J. Atomic Energy Sci. Jpn, 25(9), 709 (1983) (in Japanese).

2) T. ThOmpson and P.A. Wiberg; Tellus, 15, 314 (1963).

3) H. Hayakawa; J. Nucl. Sci. Technol., 22(4), 292 (1985).

4) S. Minato; Rep. Government Ind. Res. Inst., Nagoya, 26(9), 190 (1977) (in Japanese).

5) M.H. Wilkening and W.E. Clements; J. Geophys. Res., 80, 3828 (1975).

6) Y. Ikebe, K. Saijo, T. Iida, H. Nagai and T. TAKedA; Res. Lett. Atmosph. Electr., 5, 17 (1985).

7) UNSCEAR, 1982 Report, p. 150.

8) K. Kishibo and T. AsAi (ed.); "Taiki Kagaku Koza," Vol. 2, p.7 (1982) Tokyo Daigaku Shuppan Kai, Tokyo (in Japanese).

9) H.L. BeCK and K.M. Miller; Proc. 2nd Special Symp. on the natural radiation environment, Bombay, India (Jan. 1981), pp. 163-172 (1981).

10) K.K. Turekian, Y. Nozakı and L.K. Benninger; Ann. Rev. Earth Planet Sci., 5, 227 (1977). 